\title{
Recovery of Copper from Industrial Waste Water by Foam Flotation Process: A Review
}

\author{
Fouad S. M. Rashed ${ }^{1}$, Satyendra Nath ${ }^{2}$ \\ ${ }^{1}$ Research Scholar, Department of Environmental Science, SHIATS-Deemed University, Allahabad 211007, U.P, India \\ ${ }^{2}$ Assistant Professor, Department of Environmental Science, SHIATS-Deemed University, Allahabad 211007, U.P, India
}

\begin{abstract}
Excess copper in water is not only harmful to human beings, but also interferes with the self-purification of bulk water and adverse effect on the microbiological treatment of wastewater. Copper is an essential element but can cause adverse health effects; however, at high doses, copper can cause acute effects, such as gastrointestinal (GI) disturbances, damage to the liver and renal systems, and anemia. The price of Copper has also been increasing in the past. In view of the increasing demand, it has become essential to recover the copper metal from industrial wastes. Foam Flotation is one of the adsorptive bubble separation techniques which have many advantages such as high selectivity to remove contaminants, high overflow, low detention periods and low operating costs
\end{abstract}

Keywords: Environmental, Foam flotation, Froth flotation, Copper removal, Flotation frothers, Flotation collectors

\section{Introduction}

Due to increase in the world population and development of industrial applications, environmental pollution problem became important. The presence of toxic and polluting heavy metals in wastewaters from industrial effluents, water supplies and mine waters and their removal has received much attention in recent years. The amount of heavy metals that industrial wastewaters often contain is considerable and would endanger public health and the environment if discharged without adequate treatment.

Copper has received considerable attention owing to its uses in metallurgy, chemical industries and is necessary for other many biological important functions (Freematle, 1989; Khalifa et al., 2001). The reported list of toxic $\mathrm{Cu}$ species (Sorenson, 1991) often includes $\mathrm{Cu}(\mathrm{OH})^{+}, \mathrm{Cu}_{2}(\mathrm{OH})_{2}{ }^{2+}$ and $\mathrm{CuCO}_{3}$. However, without doubt, $\mathrm{Cu}^{2+}$ ions that are present in various aqueous solutions (their presence is a function of $\mathrm{pH})$ are considered to be the most toxic of dissolved copper species (Freematle, 1989; Khalifa et al., 2001; Sorenson, 1991). Excess copper in water is not only harmful to human beings, but also interferes with the self-purification of bulk water (Ghazy et al., 2006) and adverse effect on the microbiological treatment of wastewater (Ghazy et al., 2001) Copper is present in wastewaters of most industries such as metal cleaning and plating baths, mining and acid mine drainage, petroleum refining, paint and pigment manufacturing, motor vehicle and aircraft plating and finishing, copper ore extraction in different ranges from 0.12 $\mathrm{mg} / \mathrm{L}$ to $183 \mathrm{mg} / \mathrm{L}$. Copper may also be present in wastewaters from a variety of chemical manufacturing processes employing copper salts or a copper catalyst.

Copper is an essential element but can cause adverse health effects. The safe and adequate copper intake is 1.5 to 3 mg/day (National Research Council, 1989); however, at high doses, copper can cause acute effects, such as gastrointestinal (GI) disturbances, damage to the liver and renal systems, and anemia (Letterman et al., 1999).
Table 1: Copper Levels Reported in Industrial Wastewaters (Source: Metcalf and Eddy 2003)

\begin{tabular}{|c|c|}
\hline Industrial Source & $\begin{array}{c}\text { Copper Concentration } \\
(\mathrm{mg} / \mathrm{L})\end{array}$ \\
\hline Paint and pigment manufacturing & $0.04-100$ \\
\hline Motor vehicle and aircraft plating & $0.5-33$ \\
\hline Copper plating baths & $2.2-183$ \\
\hline Acid mine drainage & $0.12-128$ \\
\hline Petroleum refining & $0.0-1.4$ \\
\hline Copper ore extraction & $0.28-20$ \\
\hline
\end{tabular}

Copper is an essential element but can cause adverse health effects. The safe and adequate copper intake is 1.5 to 3 mg/day (National Research Council, 1989); however, at high doses, copper can cause acute effects, such as gastrointestinal (GI) disturbances, damage to the liver and renal systems, and anemia (Letterman et al., 1999).

India's copper demand was about $600,000 \mathrm{mt}$ last year. Typically, over 30 per cent of India's copper demand comes from the telecom sector and 26 per cent from the electrical sector in India. In addition, the building and construction, engineering, transport and consumer durables sectors are major consumers of copper in India.

The price of Copper has also been increasing in the past. In view of the above background it has become essential to recover the copper metal from industrial wastes.

There are various methods for removing metals from water and wastewater, e.g., chemical precipitation, ion exchange, reverses osmosis. These methods are relatively expensive, involving either costly equipment or elaborate procedures, and with some techniques, large volumes of secondary wastes are generated (Sabti et al., 2002).Flotation is one of the adsorptive bubble separation techniques which have many advantage such as high selectivity to remove contaminants, high overflow, low detention periods and low operating costs (Sulaymon and Mohammed,2010). 


\section{International Journal of Science and Research (IJSR) \\ ISSN (Online): 2319-7064}

Index Copernicus Value (2013): 6.14 | Impact Factor (2015): 6.391

\section{Past Researches}

Several researches have been done on the copper removal from wastewater using foam separation techniques. A thermodynamic approach was investigated to model the removal of cupric ion using different surfactant types and ion flotation systems by liu et al., 2001.

Doyle et al., 2003 reported that the effect of a neutral chelating ligands, triethylenetetraamine (Trien) on the ability to separate copper (II) and calcium (II) ions.

A study concerning the kinetics of $\mathrm{Cu}^{+2}$ ion separating by precipitate flotation using alkyl amine type and alkylammonium salt as cationic collectors and alkylsulphate and alkylcarboxilic type as anionic collectors was presented by Stoica et al., 2003.

Lazaridis et al., 2004 was investigated the recovery of copper ions from wastewater. They used three different mechanisms: ion flotation using xanthates, precipitate flotation generating copper hydroxide and sorptive flotation using zeolites as a sorbent material.

Ghazy et al., 2008 developed a simple, rapid and e economic procedure for copper (II) and lead (II) removal under the optimum conditions. It was based on the complex formation between $\mathrm{Cu}^{+2}$ and $\mathrm{Pb}^{+2}$ ions and diphenylcarbazone (HDPC) followed by flotation with oleic acid (HOL) surfactant.

Liu et al., 2009 investigated the Ion Flotation of $\mathrm{Co}^{+2}, \mathrm{Ni}^{+2}$, and $\mathrm{Cu}^{+2}$ using Dodecyldiethylenetriamine (Ddien), they obtained that a chelating surfactant, dodecyldiethylenetriamine (Ddien), could selectively remove one metal ion over others at different $\mathrm{pH}$ values.

A system for removal of $\mathrm{Cu}^{+2}$ from aqueous solution by foam fractionation using Dodecyl Benzenesulfonic acid (the anionic surfactant) was proposed by Zhang et al., 2009.

Abryutin et al., 2010 investigated the regularities of the ion flotation of copper by using sodium diethyldithiocarbamate (DEDTK) as the collector.

\section{Foam Floatation}

Foam flotation is a comparatively novel separation technology, first described by Sebba in 1959, for recovering and removing metal ions from dilute aqueous solutions (Bernasconi 1998; Jdid and Blazy 1990; Matis and Mavros 1991; Tessele 1998). This process involves the removal of surface inactive ion species from aqueous solution by adding the proper long chain surface active agent of opposite charge to the ion to be separated. A surface active reagent, known as collector, is added to the solution to be treated and adsorbs at the solution - gas interface. After the subsequent passage of gas bubbles through the solution, surfactant and ions are accumulated at the gas/liquid interfaces and are carried into a foam or froth, rising above the solution. The froth is swept from the top of the flotation cell. Appropriate surfactants prevent bubble rupture and promote the formation of a foam (Zouboulis 1995).

\section{Operating Principle}

Before froth flotation can work, the ore to be treated is reduced to fine particles by crushing and grinding (a process known as comminution) so that the various minerals exist as physically separate grains. This process is known as liberation. The particle sizes are typically less than $0.1 \mathrm{~mm}(100 \mu \mathrm{m})$, but sometimes sizes smaller than $7-10 \mu \mathrm{m}$ are required. This is mixed with water to form a slurry and the desired mineral is rendered hydrophobic by the addition of a surfactant or collector chemical (although some mineral surfaces are naturally hydrophobic, requiring little or no addition of collector). The particular chemical depends on the nature of the mineral to be recovered and, perhaps, the natures of those that are not wanted. This slurry (more properly called the pulp) of hydrophobic particles and hydrophilic particles is then introduced to tanks known as flotation cells that are aerated to produce bubbles. The hydrophobic particles attach to the air bubbles, which rise to the surface, forming a foam/froth. The froth is removed from the cell, producing a concentrate ("con") of the target mineral.

Frothing agents, known as frothers, may be introduced to the pulp to promote the formation of a stable froth on top of the flotation cell.

The minerals that do not float into the froth are referred to as the flotation tailings or flotation tails. These tailings may also be subjected to further stages of flotation to recover the valuable particles that did not float the first time. This is known as scavenging. The final tailings after scavenging are normally pumped for disposal.

Froth flotation efficiency is determined by a series of probabilities: those of particle-bubble contact, particlebubble attachment, transport between the pulp and the froth, and froth collection into the product launder. In a conventional mechanically-agitated cell, the void fraction (i.e. volume occupied by air bubbles) is low (5 to 10 percent) and the bubble size is usually greater than $1 \mathrm{~mm}$. This results in a relatively low interfacial area and a low probability of particle-bubble contact. Consequently, several cells in series are required to increase the particle residence time, thus increasing the probability of particle-bubble contact.

Flotation is normally undertaken in several stages to maximize the recovery of copper and the concentration of it in the concentrate, while minimizing the energy input.

\section{Stages of Flotation}

\section{a) Roughing}

The first stage is called roughing, which produces a rougher concentrate. The objective is to remove the maximum amount of copper as coarse a particle size as practical. The finer an ore is ground, the greater the energy that is required, so it makes sense to fine grind only those particles that need fine grinding. Complete liberation is not required for rougher flotation, only sufficient liberation to release enough gangue from the valuable mineral to get a high recovery.

\section{Volume 5 Issue 6, June 2016} www.ijsr.net 


\section{International Journal of Science and Research (IJSR) \\ ISSN (Online): 2319-7064}

Index Copernicus Value (2013): 6.14 | Impact Factor (2015): 6.391

The primary objective of roughing is to recover as much of copper as possible, with less emphasis on the quality of the concentrate produced.

In some concentrators, there may be a preflotation step that precedes roughing. This is done when there are some undesirable materials, such as organic carbon, that readily float. They are removed first to avoid them floating during roughing (and thus contaminating the rougher concentrate).

\section{b) Cleaning}

The rougher concentrate is normally subjected to further stages of flotation to reject more of the undesirable minerals that also reported to the froth, in a process known as cleaning. The product of cleaning is known as the cleaner concentrate or the final concentrate.

The objective of cleaning is to produce as high a concentrate grade as possible.

The rougher concentrate is often subject to further grinding (usually called regrinding) to get more complete liberation of the valuable minerals. Regrinding is often undertaken in specialized regrind mills, designed to further reduce the energy consumed during regrinding to finer sizes.

\section{c) Scavenging}

The rougher flotation step is often followed by a scavenger flotation step that is applied to the rougher tailings. The objective is to recover any of the target minerals that were not recovered during the initial roughing stage. This might be achieved by changing the flotation conditions to make them more rigorous than the initial roughing, or there might be some secondary grinding to provide further liberation.

The concentrate from the rougher scavengers could be returned to the rougher feed for refloating. Similarly, the cleaning step may also be followed by a scavenging step performed on the cleaner tailings.

\section{The Science Behind Foam Flotation}

To be effective on a given ore slurry, the collectors are chosen based upon their selective wetting of the types of particles to be separated. A good collector will adsorb, physically or chemically, with one of the types of particles. This provides the thermodynamic requirement for the particles to bind to the surface of a bubble. The wetting activity of a surfactant on a particle can be quantified by measuring the contact angles that the liquid/bubble interface makes with it. Another important measure for attachment of bubbles to particles is induction time. The induction time is the time required for the particle and bubble to rupture the thin film separating the particle and bubble. This rupturing is achieved by the surface forces between the particle and bubble.

The mechanism for the bubble-particle attachment is very complex and consists of three steps, collision, attachment and detachment. The collision is achieved by particles being within the collision tube of a bubble and this is affected by the velocity of the bubble and radius of the bubble. The collision tube corresponds to the region in which a particle will collide with the bubble, with the perimeter of the collision tube corresponding to the grazing trajectory.

The attachment of the particle to the bubble is controlled by the induction time of the particle and bubble. The particle and bubble need to bind and this occurs if the time in which the particle and bubble are in contact with each other are larger than the required induction time. This induction time is affected by the fluid viscosity, particle and bubble size and the forces between the particle and bubbles.

The detachment of a particle and bubble occurs when the force exerted by the surface tension is exceeded by shear forces and gravitational forces. These forces are complex and vary within the cell. High shear will be experienced close to the impeller of a mechanical flotation cell and mostly gravitational force in the collection and cleaning zone of a flotation column.

Significant issues of entrainment of fine particles occur as these particles experience low collision efficiencies as well as sliming and degradation of the particle surfaces. Coarse particles show a low recovery of the valuable mineral due to the low liberation and high detachment efficiencies.

\section{Theoretical Background}

\section{a) Selective adhesion}

Froth flotation depends on the selective adhesion of air bubbles to mineral surfaces in a mineral/water slurry. The air bubbles will attach to more hydrophobic particles. The attachment of the bubbles to the surface is determined by the interfacial energies between the solid, liquid, and gas phases. This is determined by the Young-Dupré Equation:

$$
\gamma_{l v} \operatorname{Cos} \theta=\left(\gamma_{s v}+\gamma_{s l}\right)
$$

Where:

- $\gamma_{l v}$ is the surface energy of the liquid/vapor interface.

- $\gamma_{s v}$ is the surface energy of the solid/vapor interface.

- $\gamma_{s l}$ is the surface energy of the solid/liquid interface.

- $\theta$ is the contact angle, the angle formed at the junction between vapor, solid, and liquid phases.

Minerals targeted for separation may be chemically surfacemodified with collectors so that they are more hydrophobic. Collectors are a type of surfactant that increases the natural hydrophobicity of the surface, increasing the separability of the hydrophobic and hydrophilic particles. Collectors either chemically bond via chemisorption to the mineral or adsorb onto the surface via physisorption. 


\section{International Journal of Science and Research (IJSR) \\ ISSN (Online): 2319-7064}

Index Copernicus Value (2013): 6.14 | Impact Factor (2015): 6.391

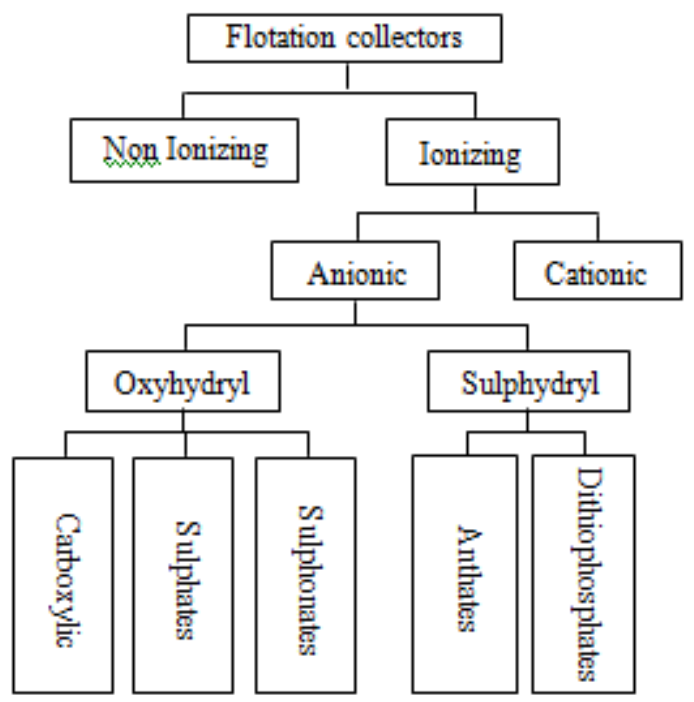

Figure 1: Different types of collectors, or surfactants, used in froth flotation

\section{b) Collision}

The collision rates for fine particles $(50-80 \mu \mathrm{m})$ can be accurately modeled, but there is no current theory that accurately models bubble-particle collision for particles as large as $300 \mu \mathrm{m}$, which are commonly used in flotation processes. For fine particles, Stokes law underestimates collision probability while the potential equation based on Surface Charge overestimates collision probability so an intermediate equation is used.

It is important to know the collision rates in the system since this step precedes the adsorption where a three phase system is formed.

\section{c) Adsorption (attachment)}

The effectiveness of a medium to adsorb to a particle is influenced by the relationship between the surfaces both materials. There are multiple factors that affect the efficiency of adsorption in chemical, thermodynamic, and physical domains. These factors can range from surface energy and polarity to the shape, size, and roughness of the particle. In froth flotation, adsorption is a strong consequence of surface energy, since the small particles have a high surface area to size ratio, resulting in higher energy surfaces to form attractions with adsorbates. The air bubbles must selectively adhere to the desired minerals to elevate them to the surface of the slurry while wetting the other minerals and leaving them in the aqueous slurry medium.

Particles that can be easily wetted by water are called hydrophilic, while particles that are not easily wetted by water are called hydrophobic. Hydrophobic particles have a tendency to form a separate phase in aqueous media. In froth flotation the effectiveness of an air bubble to adhere to a particle is based on how hydrophobic the particle is. Hydrophobic particles have an affinity to air bubbles, leading to adsorption. The bubble-particle combinations are elevated to the froth zone driven by buoyancy forces.

The attachment of the bubbles to the particles is determined by the interfacial energies of between the solid, liquid, and vapor phases, as modeled by the Young/Dupre Equation.
The interfacial energies can be based on the natural structure of the materials, or the addition of chemical treatments can improve energy compatibility.

Collectors are the main additives used to improve particle surfaces. They function as surfactants to selectively isolate and aid adsorption between the particles of interest and bubbles rising through the slurry. Common collectors used in flotation are anionic sulfur ligands, which have a bifunctional structure with an ionic portion which shares attraction with metals, and a hydrophobic portion such as a long hydrocarbon tail. These collectors coat a particle's surface with a monolayer of non-polar substance to aid separation from the aqueous phase by decreasing the adsorbed particle solubility in water. The adsorbed ligands can form micelles around the particles and form smallparticle colloids improving stability and phase separation further.

\section{d) Desorption (detachment)}

The adsorption of particles to bubbles is essential to separating the minerals from the slurry, but the minerals must be purified from the additives used in separation, such as the collectors, frothers, and modifiers. The product of the cleaning, or desorption process, is known as the cleaner concentrate. The detachment of a particle and bubble requires adsorption bond cleavage driven by shear forces. Depending on the flotation cell type, shear forces are applied by a variety of mechanical systems. Among the most common are impellers and mixers. Some systems combine the functionalities of these components by placing them at key locations where they can take part in multiple froth flotation mechanisms. Cleaning cells also take advantage of gravitational forces to improve separation efficiency.

\section{Performance calculations}

\section{a) Relevant equations}

A common quantity used to describe the efficiency of a froth flotation process is flotation recovery $(\mathrm{R})$. This quantity incorporates the probabilities of collision and attachment of particles to gas flotation bubbles.

$$
R=\frac{N_{c}}{\left(\frac{\pi}{4}\right)\left(d_{p}+d_{b}\right)^{2} H_{c}}
$$

Where:

- $N_{C}=P N_{c}^{i}$, which is the product of the probability of the particle being collected $(p)$ and the number of possible particle collisions $\left(N_{c}^{i}\right)$

- $d_{p}$ is particle diameter

- $d_{b}$ is bubble diameter

- $H$ is a specified height within the flotation which the recovery was calculated

- $c$ is the particle concentration

The following, are several additional mathematical methods often used to evaluate the effectiveness of froth flotation processes. These equations are simpler than the calculation forflotation recovery, as they are based solely on the amounts of inputs and outputs of the processes.

\section{Volume 5 Issue 6, June 2016 www.ijsr.net}




\section{International Journal of Science and Research (IJSR) \\ ISSN (Online): 2319-7064}

Index Copernicus Value (2013): 6.14 | Impact Factor (2015): 6.391

For the following equations:

- $F$ is the weight percent of feed

- $C$ is the weight percent concentrate

- $T$ is the weight percent of tailings

- $\quad c, t$, and $f$ are the Metallurgical assays of the concentrate, tailings, and feed, respectively

Ratio of feed weight to concentrate weight F/C (unit less)

$$
\frac{F}{c}=\frac{c-t}{f-t}
$$

Percent of metal recovered $\left(\mathrm{X}_{\mathrm{R}}\right)$ in wt $\%$

$$
X_{R}=100\left(\frac{c}{f}\right)\left(\frac{f-t}{c-t}\right)
$$

Percent of metal lost $\left(\mathrm{X}_{\mathrm{L}}\right)$ in wt\%

$$
X_{L}=100-X_{R}
$$

Percent of weight recovered $\left(\mathrm{X}_{\mathrm{W}}\right)$ in wt\%

$$
X_{W}=100\left(\frac{C}{F}\right)=100\left(\frac{f-t}{c-t}\right)
$$

\section{b) Grade-recovery curves}

Grade-recovery curves are useful tools in weighing the trade-off of producing a high grade of concentrate while maintaining as low of a recovery rate as possible, two important aspects of froth flotation. These curves are developed empirically based on the individual froth flotation process of a particular plant. As the curves are shifted in the positive $\mathrm{x}$-direction (to the right) and the positive $\mathrm{y}$-direction (upward) the performance of the froth flotation process is regarded as improving. A disadvantage to these curves is that they can only compare the grade-recovery relations of a specific feed grade and feed rate. If a company has a variance of feed grades and rates used (an extremely common occurrence) in their froth flotation process, graderecovery curves for every pairing of feed grade and recovery rate would have to be constructed in order to provide meaningful information to the plant.

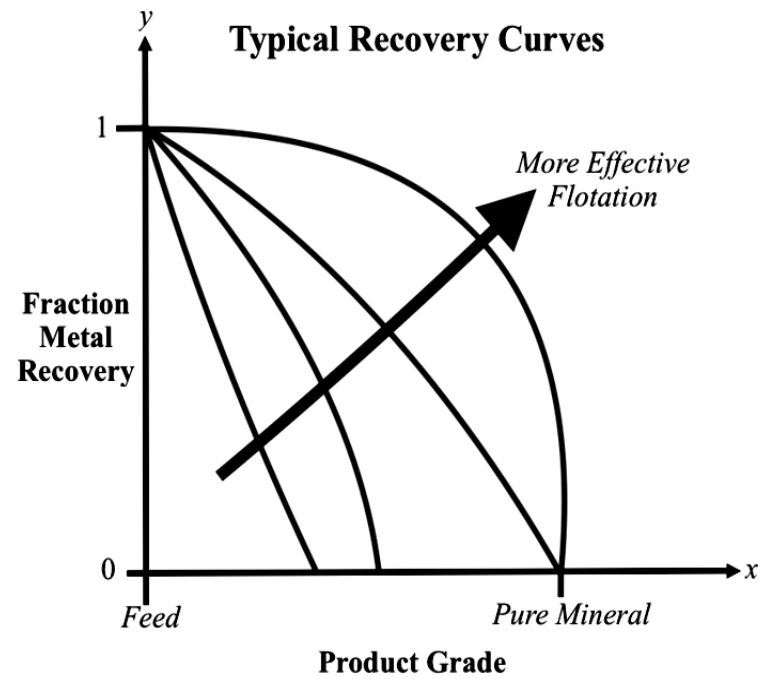

Figure 2: Example of grade-recovery relationships seen in froth flotation is indicated above. Shifts in the curves represent changes in flotation effectiveness.

\section{Flotation Equipment}



Figure 3: Diagram of froth flotation cell.

Numbered triangles show direction of stream flow. A mixture of copper salt and water called pulp enters the cell from a conditioner, and flows to the bottom of the cell. Air or nitrogen is passed down a vertical impeller where shearing forces break the air stream into small bubbles. The copper-concentrate froth is collected from the top of the cell, while the pulp flows to another cell.

Flotation can be performed in rectangular or cylindrical mechanically agitated cells or tanks, flotation columns, Jameson Cells or deinking flotation machines. Classified by the method of air absorption manner, it is fair to state that two distinct groups of flotation equipments have been used: pneumatic and mechanical. Generally pneumatic machines give a low-grade concentrate and little operating troubles.

Mechanical cells use a large mixer and diffuser mechanism at the bottom of the mixing tank to introduce air and provide mixing action. Flotation columns use air spargers to introduce air at the bottom of a tall column while introducing slurry above. The countercurrent motion of the slurry flowing down and the air flowing up provides mixing action. Mechanical cells generally have a higher throughput rate, but produce material that is of lower quality, while flotation columns generally have a low throughput rate but produce higher quality material.

The Jameson cell uses neither impellers nor spargers, instead combining the slurry with air in a downcomer where high shear creates the turbulent conditions required for bubble particle contacting.

\section{Mechanics of flotation}




\section{International Journal of Science and Research (IJSR) \\ ISSN (Online): 2319-7064}

Index Copernicus Value (2013): 6.14 | Impact Factor (2015): 6.391

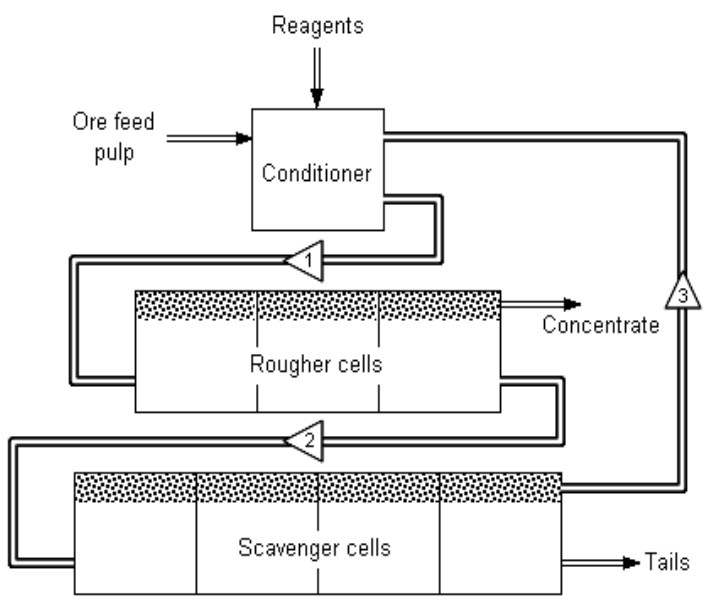

Figure 4: Simple flotation circuit for mineral concentration

Numbered triangles show direction of stream flow, Various flotation reagents are added to a mixture of ore and water (called pulp) in a conditioning tank. The flow rate and tank size are designed to give the minerals enough time to be activated. The conditioner pulp is fed to a bank of rougher cells which remove most of the desired minerals as a concentrate. The rougher pulp passes to a bank of scavenger cells where additional reagents may be added. The scavenger cell froth is usually returned to the rougher cells for additional treatment, but in some cases may be sent to special cleaner cells. The scavenger pulp is usually barren enough to be discarded as tails. More complex flotation circuits have several sets of cleaner and re-cleaner cells, and intermediate re-grinding of pulp or concentrate.

\section{Chemicals used in the foam flotation process}

\section{a) Collectors}

Mostly, the collectors are anionic sulfur ligands. Particularly popular are xanthate salts, including potassium amyl xanthate (PAX), potassium isobutyl xanthate (PIBX), potassium ethyl xanthate (KEX), sodium isobutyl xanthate (SIBX), sodium isopropyl xanthate (SIPX), sodium ethyl xanthate (SEX). Other collectors include related sulfurbased ligands: dithiophosphates, dithiocarbamates. Still other classes of collectors include the thiourea thiocarbanilide. Fatty acids have also been used.

\section{b) Frothers}

A variety of compounds are added to stabilize the foams. These additives include pine oil, various alcohols (methyl isobutyl carbinol (MIBC)), polyglycols, xylenol (cresylic acid).

\section{c) Modifiers}

A variety of other compounds are added to optimize the separation process, these additives are called modifiers. Such species do not interact directly with the mineral, but modify the physical properties of the solution.

- $\mathrm{pH}$ modifiers include lime $(\mathrm{CaO})$, Soda

Ash $\left(\mathrm{Na}_{2} \mathrm{CO}_{3}\right)$, Castic

Soda $(\mathrm{NaOH})$, Sulfuric and Hydrochloric acid $\left(\mathrm{H}_{2} \mathrm{SO}_{4}\right.$, $\mathrm{HCl})$.
- Anionic modifiers include phosphates, silicates, and carbonates.

- Organic modifiers include the thickeners dextrin, starch, glue, and CMC.

\section{Scale-up of Flotation Processes}

Due to the wide range of systems utilizing flotation separation, the equipment used for the process varies. It can be classified based on the method to generate and to introduce the gas bubbles (dissolved-air, forced injection, suction), the level of turbulence (impeller or impellerless), relative direction of phase movement (reactor-separator, bank of several cells, countercurrent column). Capacities of the machines can be as little as a portion of a cubic centimeter or as large as several hundreds of cubic meters. All of the above makes creating the techniques for flotation scale-up particularly challenging. In addition to that, unlike many other separation processes, increased duration of the flotation separation does not necessarily improve its metallurgical results. While this is generally true for waste water treatment, raising the time of bubble/particle exposure in mineral flotation typically increases the recovery of component to be collected with the froth, but leads to product grade deterioration. Therefore, determining the correct arrangement and size of the flotation cells based on batch and pilot test results (scaling-up) is extremely important for the overall results. Scale-up should also include a methodology to optimize the flow sheet which (in case of mineral flotation) typically includes rougher, scavenger and cleaner stages with recycling of intermediate products into the previous stage (optionally including additional reagent treatment and/or regrinding). Despite all considerations, the typical approach is to determine the "right" parameters in lab-scale tests (including conditioning and separation time, etc.) and then to apply them to the industrial-scale operation using an empirical "scale-up factor". Based on the complexity and multifaceted nature of the problem, hierarchical model is required to analyze all the aspects and to propose a reliable scale-up approach.

The simplest approach is to consider flotation as the process following the first-rate kinetics. Assuming that particles do not interact with each other and do not "compete" for the space on bubble surface (in slurry and in froth), this approach is adequate under steady-state conditions (i.e., the stable froth has been formed and is discharging, gas holdup and velocity distribution reached the final pattern, etc.). Rate of the first-order kinetics equation (often referred to as flotation rate $\mathrm{K}, \mathrm{min}-1$ ) represents a probability of a particle (more precisely, a unit mass of the component in question) transfer into concentrate per unit time. Change of the constant depending of the scale of the flotation machine is the factor determining the scale-up considerations. It should be noted that (unlike reaction rates in chemical engineering) flotation rate depends upon particle composition and size as well as upon its surface properties, reagent adsorption and other factors. Therefore, each component may be represented by its continuous flotation rate distribution $\mathrm{F}(\mathrm{K})$. Formally speaking, deformation of this set of distributions at scale-up 


\section{International Journal of Science and Research (IJSR) \\ ISSN (Online): 2319-7064}

Index Copernicus Value (2013): 6.14 | Impact Factor (2015): 6.391

is determining results of industrial scale process based on given pilot/batch results. Given the identical chemical environments, this deformation can be attributed to the differences in aeration and hydrodynamics between machines of different scale. Analysis of the differences should be based on studying the physics of the flotation process. In addition to that, at continuous flotation, particle retention time is not constant (unlike at batch flotation experiments); hence, dispersion of the residence time distribution (RTD) E(t) should be taken into consideration as the factor reducing metallurgical performance (both recovery and grade) comparing to those in batch tests under the identical otherwise conditions and flotation time.

\section{References}

[1] G. J. Jameson, "Flotation cell development," in: The AusIMM Annual Conference, Broken Hill, New South Wales, 17-21 May 1992 (The Australasian Institute of Mining and Metallurgy: Melbourne, 1992), 25-31.

[2] Wales - The birthplace of Flotation". Retrieved 13-12010.

[3] Rickard, Thomas A. (1922). Interviews with Mining Engineers. San Francisco: Mining and Scientific Press. pp. 119-131.

[4] Osborne, Graeme (1981). "Guillaume Daniel Delprat". Australian Dictionary of Biography. Canberra: Australian National University. Retrieved 7 June 2012.

[5] "Historical Note". Minerals Separation Ltd. Retrieved 2007-12-30.

[6] Callow; 1916

[7] Rickard, Thomas A. (1922). Interviews with Mining Engineers. San Francisco: Mining and Scientific Press. p. 142.

[8] A detailed description of the history of flotation and this process can be found in Callows "Notes on Flotation" found in the Transactions of the American Institute of Mining Engineers; Vol. 53-54, originally presented in New York in February 1916.

[9] Wills, B A; Atkinson, K (1991). "The development of minerals engineering in the 20th Century". Minerals Engineering 4:643-652. doi:10.1016/0892 6875(91)90054-y.

[10] Beychok, Milton R. (1967). Aqueous Wastes from Petroleum and Petrochemical Plants (1st ed.). John Wiley \& Sons Ltd. LCCN 67019834.

[11] Voith EcoCell flotation plant http://www.voithpaper.com/applications/productsearch /files/594_VPR-PB-07-0001-GB-07.pdf

[12] D N Nihill, C M Stewart and P Bowen, "The McArthur River mine - the first years of operation," in: AusIMM '98 - The Mining Cycle, Mount Isa, 19-23 April 1998 (The Australasian Institute of Mining and Metallurgy: Melbourne, 1998), 73-82.

[13] Yianatos J.B., Bergh L.G., Aguilera J. Flotation scale up: use of separability curves, Min. Eng., 16, 347-352 (2003).

[14] Rubinstein J. B. Column flotation: Processes, Design and Practives, 204-221 (1995).

[15] Nguyen P.T., Nguyen A.V. Validation of the generalised Sutherland equation for bubble-particle encounter efficiency in flotation: Effect of particle density, Minerals Engineering 22, 176-181 (2009)

[16] Derjaguin, B. V. , Dukhin, S. S. , Rulyov, N.N. in: E. Matejevic, R.J. Good (Eds.), Surface and Colloid Science, Vol. 13, Wiley-Interscience, New York, 1984, Chap. 2

[17] Pyke B., Fornasiero D., Ralston J. Bubble particle heterocoagulation under turbulent conditions, Journal of Colloid and Interface Science 265, 141-151 (2003).

[18] Samygin V.D., Margulis L.G., Burstein M. Calculation of flotation rate constant according to the subprocess structure with accounting the space heterogeneity, Izv. Vuzov. Tzvet. Metall. 2, 12-18 (1985).

[19] Lazaridis, N.K., Peleka, E.N., Karapantsios, Th.D. and Matis K.A., 2004. Copper removal from effluents by various separation techniques. Hydrometallurgy, 74: 149-156.

[20] E V Manlapig, C Green, J W Parkinson and A S Murphy, "The technology and economic incentives for recovering coal from tailings impoundments," SME Annual Meeting, Denver, Colorado, 26-28 February 2001, Preprint 01-70 (Society of Mining, Metallurgy and Exploration: Littleton, Colorado, 2001).

[21] B W Atkinson, C J Conway and G J Jameson, response, "in: Sixth Australian Coal Preparation Conference, Mackay, Queensland, 6-9 September 1993 (The Australasian Institute of Mining and Metallurgy: Melbourne, 1993). 